\title{
Leap-frogging or Limping? Recent Evidence from the Lapita Littoral Fringe, New Georgia, Solomon Islands
}

\author{
Matthew Felgate
}

Felgate and Associates

P.0. Box 3155,

Shortland Street Mail Centre,

Auckland, New Zealand.

felgate@xtra.co.nz

\section{Introduction}

Lapita pottery is a component of an archaeological horizon-style found from the Bismarck Archipelago to Samoa, dating to approximately 3300-2700 BP. Lapita pottery marks the first human colonisation of Remote Oceania (Figure 1), that part of the Pacific that cannot be reached other than by making lengthy ocean crossings (Green 1991b) indicating that this pottery style was correlated in Remote Oceania with a maritime colonising cultural adaptation and a period of rapid expansion (Green 1991a). Near Oceania has by contrast been occupied for about 30000 years, at least as far to the southeast as Buka, to the north of Bougainville (Allen et al. 1989; Wickler 1995, 2001; Wickler and Spriggs 1988), thus requiring a more complex model of local formation of the maritime colonising adaptation, incorporating intrusive Island-Southeast-Asian Neolithic elements, local innovations, and integration with pre-existing indigenous populations (Green 1991a).

\section{Lapita and Solomon Islands: The Lapita Gap}

Establishing the distribution of the Lapita Pottery horizon has been a major goal of Pacific archaeology since the 1950s. The Near Oceanic Solomon Islands (the Solomon Islands including Bougainville and excluding Ontong Java, Te Motu Province and Rennell-Bellona) comprise a major gap in the recorded distribution of early-Lapita pottery sites (Green 1978; Kirch 1997:53; Kirch and Hunt 1988; Roe 1992, 1993; Spriggs 1997:128). More recently the argument has been made extensively, with supporting data, that this gap in the record is explicable as an artefact of predominantly stilt-village early-Lapita settlement pattern in Near Oceania, with consequent poor detectability of early sites by the usual terrestrial targeted survey methodology (Felgate 2001, 2003; Felgate 


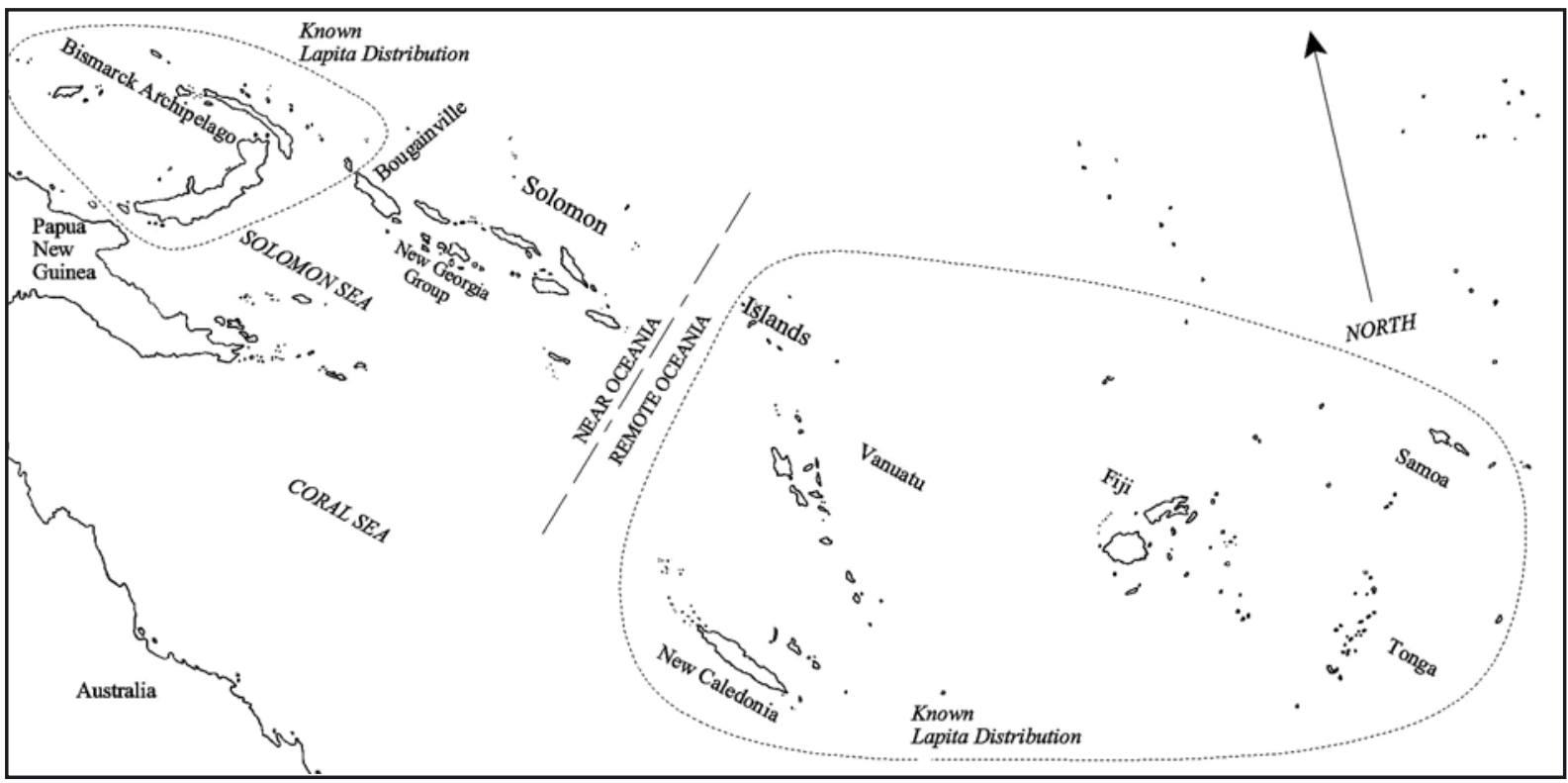

Figure 1. Map of Near/Remote Oceania showing the recorded distribution of Lapita pottery prior to the New Georgia Archaeological Survey.

and Bickler n.d). The view persists, however, that early-Lapita period colonisers avoided the near-Oceanic Solomon Islands, although a late-Lapita presence is now acknowledged (Sheppard and Walter 2006).

Whether the distribution of early-Lapita pottery was continuous or discontinuous in Near Oceania is a primary issue, as it has significant implications for our ideas about what Lapita represents. A continuous distribution of early-Lapita pottery across this region would favour a model of the largely indigenous development of Lapita pottery, or at least raise the probability of integration into local populations of any migrants from Island Southeast Asia at an early stage in the development of the Lapita cultural complex. A discontinuous distribution would favour an avoidance model of Lapita colonisation (e.g. Sergeantson and Gao 1995:169), where Lapita represents "foreign" intrusion, by an expansionist society living at the fringes of an already occupied hostile and / or malarious Near-Oceanic Solomon Islands. In this sort of model Lapita expansion "colonies" are seen as confined initially mostly to offshore islands in the Bismarck Archipelago, and remain culturally and genetically relatively distinct from earlier occupants of Near Oceania for an extended period; generally bypassing the bulk of the Near Oceanic Solomon Islands in favour of a previously unoccupied and / or otherwise healthier Remote Oceania.

Opinion amongst archaeologists with an interest in Lapita is divided as to the reasons for the gap in the distribution of early Lapita sites. Two possible explanations commonly discussed previously are (a) that the gap is purely an artefact of insufficient survey in this region (Green 1978; Spriggs 1997:128) and (b) that the gap directly reflects a discontinuous distribution of Lapita in this region or even complete avoidance of this region by Lapita peoples in the past (Gorecki 1992; Roe 1992, 1993:185; Sheppard and Walter 2006; Sheppard et al. 1999). Some take an equivocal position in relation to these possibilities (e.g. Kirch 1997:53). An additional possibility less often considered is (c), that tectonic instability has reduced coastal site visibility / preservation in the Near-Oceanic Solomon Islands (Kirch and Hunt 1988:18).

Discussion has been conditioned until recently by the complete lack of Near-Oceanic Solomon Islands Lapita pottery discoveries. This allowed considerable scope for theories explaining the lack of Lapita pottery sites as avoidance of the area by Lapita-using people. For example, at the 1996 Port Vila Lapita conference, the first two field seasons of the Roviana Archaeological survey were summarised, concluding, among other things, that, 
"The Roviana survey, like all previous work by archaeologists - including the considerable fieldwork by the Solomon Islands National Museum and Ministry of Culture, Western Province, has failed to recover any Classic Lapita dentate-stamped ceramics in the Western Solomons. I would add this data to that from the central Solomons and extend Roe's (1993) hypothesis of no Lapita occupation in the central Solomons to include the Western Solomons. If this hypothesis is correct it adds an interesting wrinkle to the Lapita expansion story and forces us to consider the effect of interaction of Lapita with established populations....I seems possible that the colonisation of the Reefs/Santa Cruz (Green 1979) may mark a very big first step, leap-frogging previously established populations and cultural networks" (Sheppard et al. 1999).

Subsequent to that paper I continued to focus my efforts under the umbrella of the same project on the intertidal and shallow water pottery scatters initially investigated in the 1980s (Reeve 1989), and re-examined in the course of the first seasons of the Roviana survey, when a number of additional similar sites were found by the team (Felgate 2002, 2003, Felgate and Bickler n.d; Felgate and Dickinson 2001; Sheppard et al. 1999). A small number of dentate sherds were recovered from various sites in the course of that work by various members of the team, and one shallow-water site, at Honiavasa in Roviana Lagoon, yielded more substantial evidence for Lapita occupation. At about the same time Ian Scales of the Australian National University was undertaking a roving extended four-fields study of the Western Solomons, and discovered two early pottery sites in the sea at Kolombangara, in the Western Solomons (Figure 2), one of which (Poitete), Summerhayes and Scales suggest, and I agree, has affinities to the Honiavasa site (Summerhayes and Scales 2005).

These finds have had little effect on the leap-frogging theory, most recently stated as:

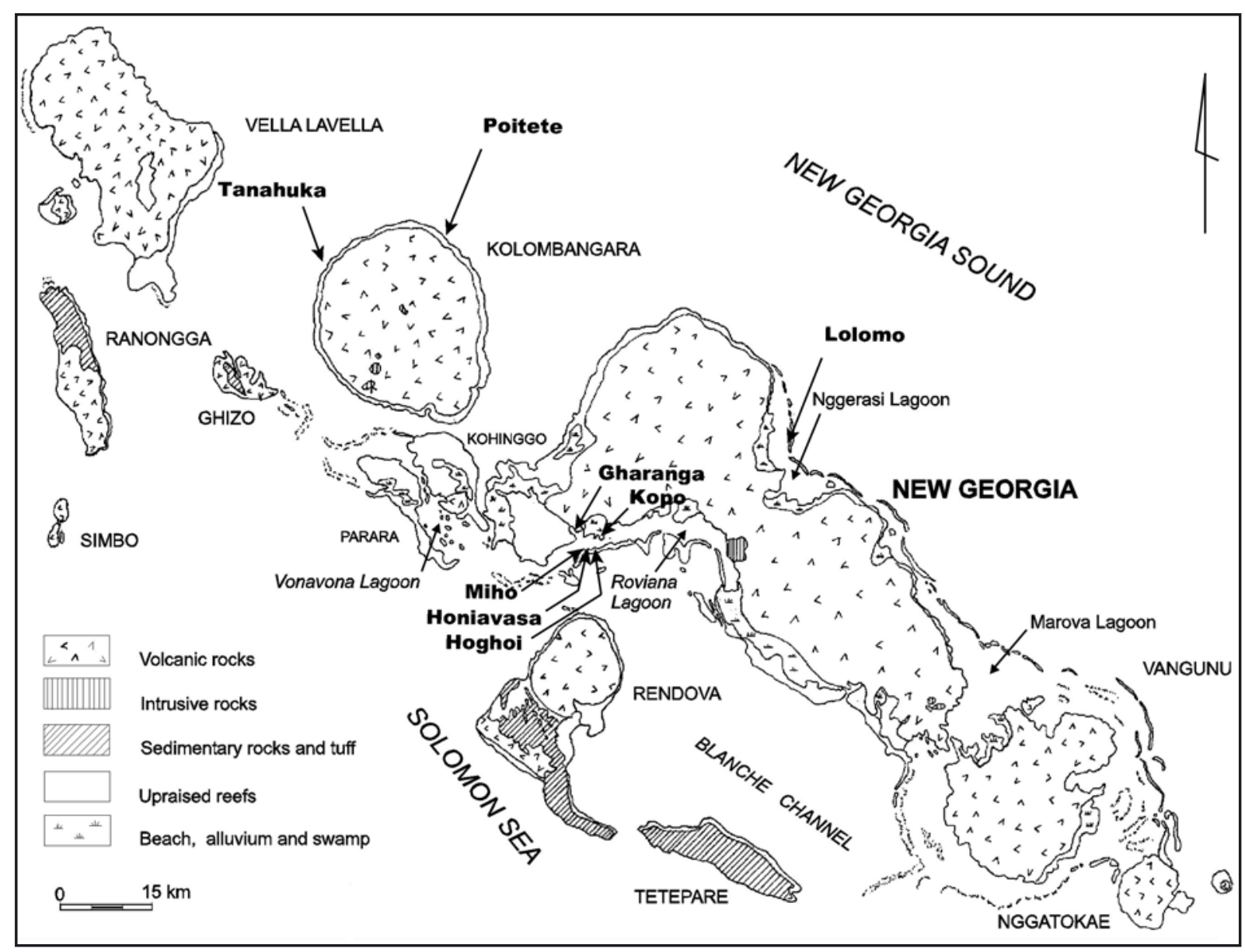

Figure 2. Geology of New Georgia, showing locations of Roviana Lagoon and Nggerasi Lagoon. 
"The Lapita occupation of the Reef/Santa Cruz Islands in the early Lapita period leapfrogged the main Solomons, giving it some unique characteristics of significance for colonization of Remote Oceania" (Sheppard and Walter 2006)

The principal revision is the use of the word "Early" instead of "Classic". The prospect of spectacular future early-Lapita finds from the sea in the Near-Oceanic Solomon Islands is not predicted by this model.

We have no evidence yet that early Lapita was absent from the Western Solomons. Sheppard and Walter stress the differences between the Buka reef sites and RF-2 in the Reef Islands, and while pointing out that DJQ on Buka has a high ratio of dentate-to-incised decoration, approaching that of the early Reef/ Santa Cruz sample, argue that this site (undated in terms of any absolute technique) is much later than RF2. I have gone over the similarities between Buka, Honiavasa, Tongan and New Caledonian Lapita vessel forms elsewhere (Felgate 2003:500), and the evidence for regionalisation across time in Wickler's data (Felgate 2003:128). I feel the difference between RF2 and the Near-Oceanic Solomons Lapita sites is overstated given that the Lapita sites of the Western Solomons are undated by any absolute technique. Only two sites in the Western Solomons of the many intertidal sites recorded can be ascribed confidently to the Lapita period on the basis of form or decoration (Honiavasa and Poitete) as opposed to being later sites with the occasional Lapita sherd present, so I would regard our current sample from the area of the Lapita period as unsaturated in Kintigh's sense (Kintigh 1984).

The linguistic scenario as constructed by Tryon and Hackman is for a higher-order subgrouping of the Austronesian languages of Bougainville, the Western Solomons and New Ireland (Tryon and Hackman 1983:54), later all included under the wider subgroup "Meso-Melanesian" as its "South New Ireland/ NorthWest Solomonic Network" (Ross 1988:259). The languages of the Southeast Solomons by contrast are classified separately, sometimes together with the languages of northern and central Vanuatu, Fijian and the languages of Polynesia (Tryon and Hackman 1983:53-54). Northern Ysabel languages just to the north of the Tryon/ Hackman linguistic boundary constitute the late front of Meso-Melanesian language expansion.

Sheppard and Walter see a correlation between the Tryon-Hackman linguistic boundary and the absence of ceramics in the known archaeological record of the Near-Oceanic Solomon Islands to the south of this line, together with the presence of ubiquitous late (post $550 \mathrm{BP}$ ) terrestrial ceramic deposits north of the line. They suggest a revision of Tryon's and Hackman's linguistic interpretation of a late Meso-Melanesian southward expansion largely obliterating a previous SE Solomonic substrate north of the Tryon-Hackman line, preferring to see the linguistic boundary as a meeting of eastwards expansion of Late Lapita with westwards aceramic back-migration of Southeast Solomonic speakers whose ancestors lost pottery very early, after leapfrogging the Near-Oceanic Solomons and settling Remote Oceania via the Reef-Santa Cruz Islands. They suggest the reason for this ceramic and linguistic distribution is a lack of early Lapita settlement in the entire Near-Oceanic Solomons area, with settlement north of the line by Lapita people late in the series. They imply that the reason for the presence of late terrestrial ceramics north of the Tryon-Hackman linguistic boundary is a cultural hangover from late-Lapita settlement in that area alone. As supporting evidence they note the widespread use of the word "Raro" (pot) in the Meso-Melanesian languages of the west and Bougainville, and the absence of pottery terms in SE Solomonic languages.

I prefer the theory that the late terrestrial pottery ubiquitous in the west is a feature of a late MesoMelanesian-speaking cultural expansion, (beginning sometime post-Lapita), and having strikingly similar archaeological expression in the megalithic architecture of South Bougainville as documented in John Terrell's $\mathrm{PhD}$ thesis (Terrell 1976). Sheppard and Walter are arguing for cultural continuity between the early ceramics in the sea and the late ceramics on land, but what is the explanation for abandonment of this intertidal pattern and development of megalithic Tambu places and terrestrial ceramic deposition in the West Solomons and Bougainville? I think there is a fundamental question here concerning cultural continuity rather than current data providing an answer. 
One possible environmental or human biogeographic explanation for a theory of late expansion of the Meso-Melanesian linguistic grouping can be constructed by turning to the ethnological distribution of canoe types. Nissan, an atoll between Bougainville and the Bismarcks, is an outlier in the distribution of twinoutrigger trimaran-style of canoes as used in ethnohistoric times around the margins of the Arafura sea, north to the Philippines and west to Madagascar/east Africa (Doran 1973:40). In addition to this possibly intrusive type, the Near-Oceanic Solomon Islands had, at contact, monohull plank-built canoes rather than dugouts (on both sides of the Tryon-Hackman Line (Haddon and Hornell 1937:332). The smaller plank-built fishing canoes in this distribution (the Mola in Roviana language) have a pan-Solomonic similarity in being based on a flatbottomed keel plank, with a deadrise plank and a topside plank added on either side, with additional raised planks at bow and stern. The Roviana Hore, or dugout, similarly has a pan-Solomonic distribution in recent times. The antiquity of these distributions is presently unknown.

The Tomoko is a large war canoe carrying about thirty paddlers (Waterhouse 1949). It is, in its general structure and design, a complete contrast to the Mola and Hore. It can be classified as a keel-ship (Doran 1973), being of very complex sewn-plank construction on a vertically oriented central keel. These war-canoes are similar in a functional sense, although the similarity is analogous rather than homologous, to the New Zealand Maori Waka Taua. Like the Waka Taua, they have their origins outside the tradewind belt, and can maintain high speeds in calm or windless conditions, giving their users a strategic advantage and greater raiding range in calm conditions over users of outrigger canoe types.

Tomoko have not been recorded south of the Tryon-Hackman line, but are distributed throughout the Western Solomons north of the line, and provide a mechanism for the expansion of the Meso-Melanesian Languages, as a late-prehistoric torrid-zone war vessel. I find the idea tempting that the spread of the Tomoko, the Meso-Melanesian Languages, and the megalithic Tambu places in Bougainville and the Western Solomons may have happened at about the same time. These Tomoko may have a homologous relationship to Indic construction techniques of Island Southeast Asia, and may have been introduced to the area long after the spread of singleoutrigger technology into Remote Oceania circa 3000 BP. Hornell drew attention to the similarities with ancient craft of Scandinavia regarding the general classification of the construction techniques, and suggested a close (homologous?) similarity of this advanced type of construction to canoes recorded from the island of Botel Tobago near Taiwan and also the Moluccan Orembai (Hornell 1936).

The theory of a later expansion of the Meso-Melanesian languages, during which NAN languages survived in pockets, begs the question of why no SE Solomonic survivals north of the Tryon Hackman Line. The saltwater/bush dichotomy may have made any SE-Solomonic speaking communities north of the TryonHackman line more vulnerable to language-loss than NAN bush-dwellers. Some of the NAN languages (Kazukuru, for example) are regarded today as languages of inland-dwellers, with an uneasy relationship to coastal Meso-Melanesian speakers in the ethnohistoric period. Kenneth Roga and I interviewed a very elderly man in 1996, reputed to be the last survivor in Roviana of inland people who moved to the coast after pacification of the area. He told how inland women and lagoon women exchanged resources in an uneasy truce while the respective male warriors stood back on each side ready for any sign of conflict. The coastal people had limited access to bush resources and the bush people to marine resources even in the early mission period as a result of this uneasy relationship, and bush people were clearly distinct and not to be trifled with in the early $20^{\text {th }}$ century. It is possible that such relationships extended back into the distant past, and that the Meso-Melanesian expansion was primarily coastal, at the expense of earlier more vulnerably-located coastal languages of the SE Solomonic subgroup. This very point is in fact made on linguistic grounds by Ross (1988:384-385).

The absence of terrestrial and ethnohistoric ceramic traditions south of the Tryon Hackman line is consistent with the record from the Reef/Santa Cruz area of pottery being lost relatively rapidly after the Lapita period, if it is accepted that Lapita and post-Lapita settlement south of the Tryon/Hackman line in the Near-Oceanic Solomon Islands was predominantly over the water, and did not create a terrestrial ceramic 
record (there seems to be accumulating evidence for this now from the Western Solomons). The question now is whether relative sea-level studies of the last 3000 years in the area will offer support to such a model. Such studies have not yet been carried out, and existing information (Mann et al. 1998) is not specifically directed at this period and provides sparse and contradictory results for late sea level changes, of limited relevance to this archaeological question. Detailed sea-level studies and appropriately targeted intertidal/underwater surveys from south of the line are needed to test such a sweeping revision of the Solomons linguistic sequence.

\section{Dating the Honiavasa site}

Elsewhere I have referred to the Honiavasa site, situated at the main entrance passage to Roviana Lagoon, as a late Lapita site, as have Summerhayes and Scales, but it is worth noting that chronological assignment is based principally on seriation chronologies of ceramic attributes. A radiocarbon date was obtained from surface soot on a plain sherd from the Hoghoi site at Roviana lagoon (NZA12353: $2619 \pm 45 \mathrm{BP}$ ) which calibrates to $2900 \mathrm{BP}$ (86.7\%) $2780 \mathrm{BP} ; 2690 \mathrm{BP}(3.5 \%) 2660 \mathrm{BP} ; 2640$ BP (3.6\%) 2590 BP; 2580 BP (1.6\%) 2550 BP using atmospheric data from Stuiver et al. (1998), OxCal version 3.10 (Bronk Ramsey 2005). This determination is thought to post-date the Honiavasa site on the basis of a seriation chronology, used in conjunction with a relative chronology obtained from thermoluminescence dates of quartz-calcite hybrid tempered sherds (Felgate 2003:451-481).

While this data is reassuring in that it reinforces the notion that no gross chronological error has been made in assigning Honiavasa to the Lapita period, it does not inform as to the age of the site in relation to other Lapita sites, leaving artefact and stylistic studies as the principal method for chronological comparisons (although there is some potential for thermoluminescence relative chronologies for granitic-tempered sherds, and for calibrated calendrical dates if an adequate model of fading can be developed for this specific temper type, especially the potassium feldspar grains).

Examples of Miho, Gharanga and Kopo styles are shown in Figures 3-5. The

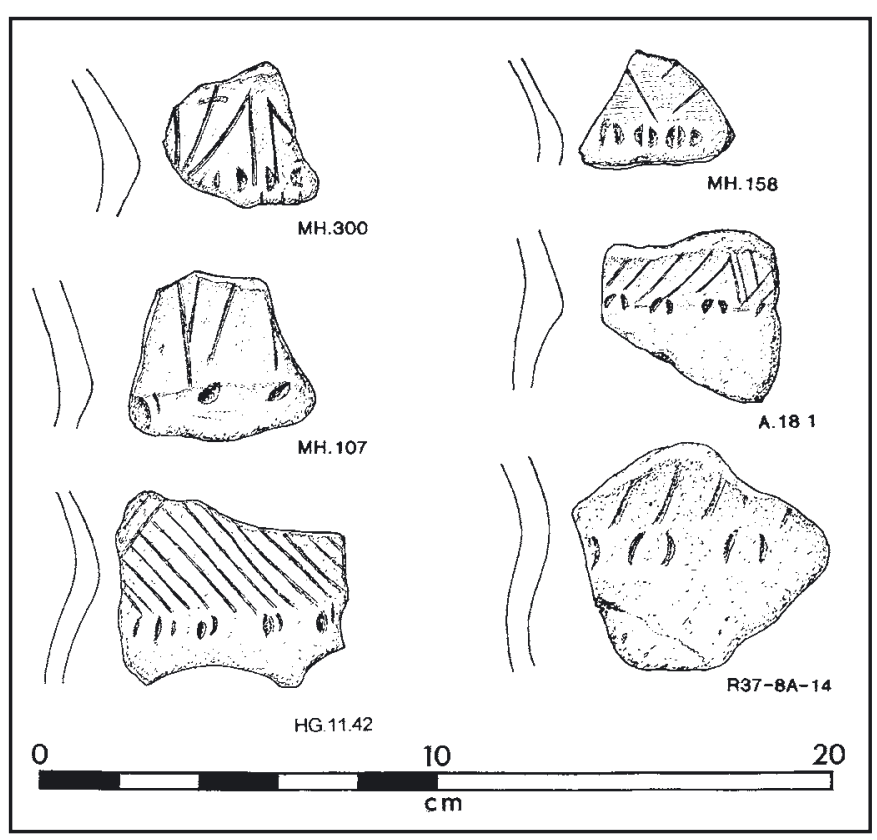

Figure 3. Miho-style sherds from Roviana Lagoon.

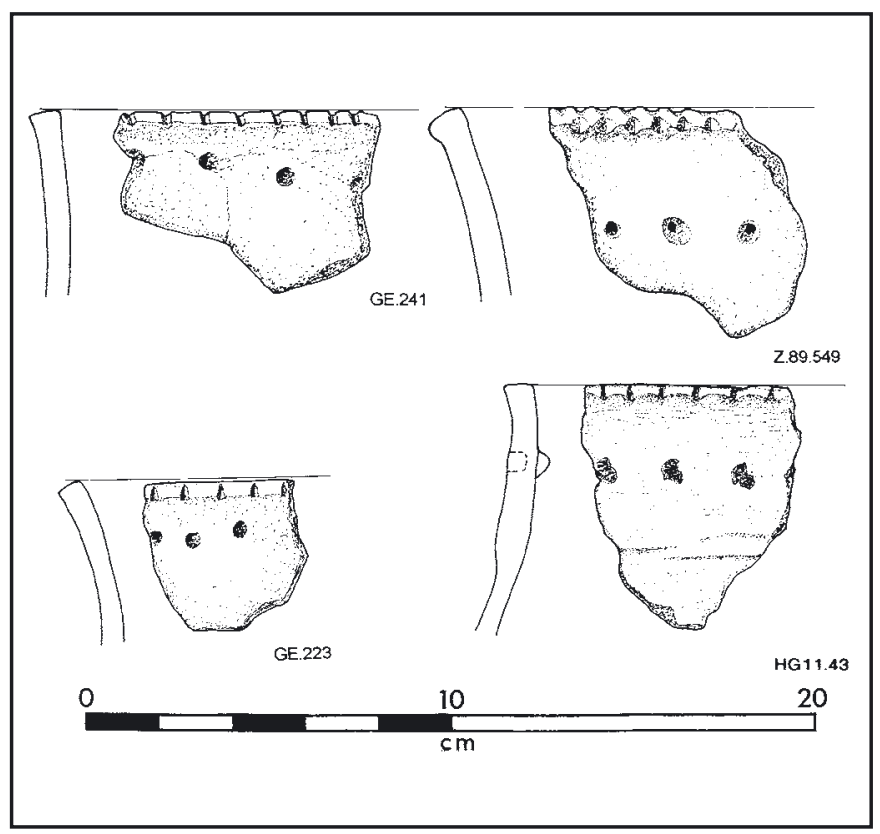

Figure 4. Kopo-style sherds from Roviana Lagoon. 


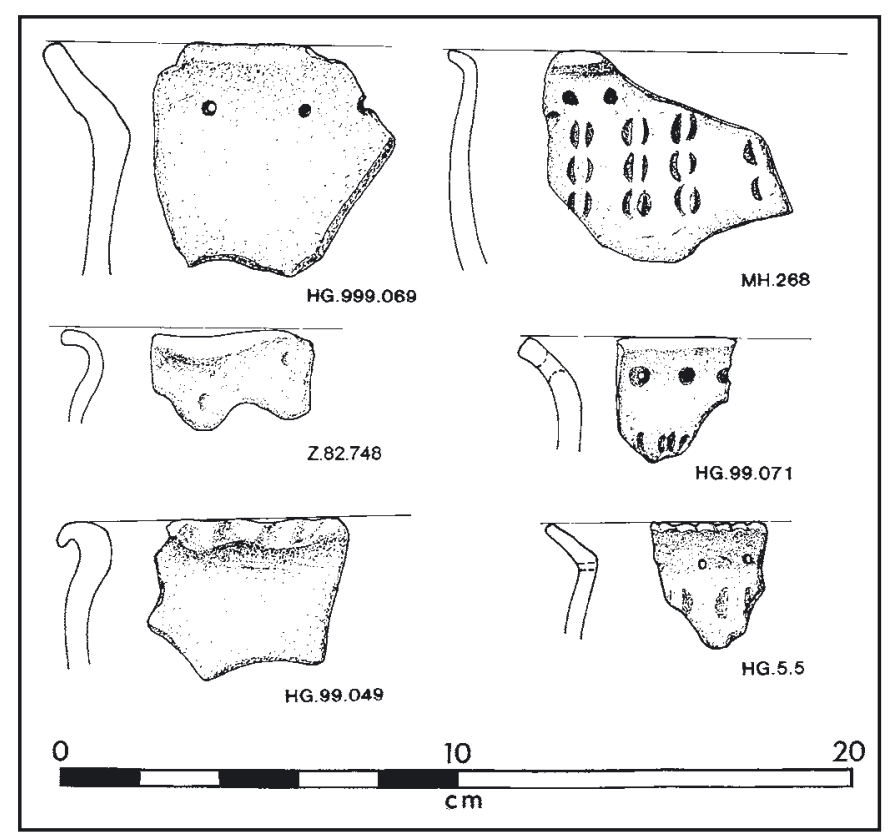

Figure 5. Gharanga-style sherds from Roviana Lagoon. sequence in which Gharanga and Kopo occur is uncertain, but a phyletic series from Honiavasa Lapita bounded decoration to Miho, followed by Gharanga/Kopo seems to be the most economical arrangement. The positioning of these other styles later than Honiavasa in the series is well supported by thermoluminescence data. Mihophase decoration may be homologous/ contemporaneous with Wickler's unbounded incised decoration at DAF on Buka (Wickler 2001:112-113) while Gharanga-Kopo punctate necks may relate to two sherds found at DES (Wickler 2001:120). Wickler noted the similarity between these sherds and some from Lapita sites in the Bismarck Archipelago.

New vessel-form evidence presented in this paper from the Lolomo underwater site at North New Georgia (an annotated aerial view of the site is shown in Figure 6) suggests that the dated sherd from Hoghoi is intermediate between the Miho and Gharanga phases of the Roviana sequence (for a fuller discussion of the chronological issues see Felgate 2003: Chapters 12 and 13) and thus post-dates the Lapita pottery at Honiavasa by a substantial margin. The Hoghoi vessel which was dated is illustrated in Figure $7 \mathrm{~b}$ together with some other Roviana neck and rim sherds having similar characteristics. None of the other Roviana sherds provide a robust match to the dated sherd, which combines the thin body, neck and rim of the Gharanga style with the tall fragile rim form of the Miho style, but has, like the Gharanga style, a pronounced vertical curve at the neck, rather than the gentler curve of the Miho style, and lacks the local thickening of the neck profile so characteristic of the Miho style (rendering neck sherds weaker and thus biasing assemblages against this neck type).

Figure 7a shows a sherd from Paniavile at Roviana lagoon with a fairly thin neck and fairly tight vertical curve at the neck which bears comparison with the dated Hoghoi sherd (Figure 7b). Figure 7c shows a flat-lipped sherd from the Honiavasa Lapita site, which has the pronounced neck with thin and excurvate tall rim of the dated Hoghoi sherd, but is virtually unique among the Roviana ceramics by virtue of its lip form, and which is made using an exotic sand temper of the anomalous Quartz-Calcite hybrid class (Felgate and Dickinson 2001). Figure 7d from Honiavasa is of the right general neck form, but has a very small orifice diameter and is much thicker than the dated Hoghoi sherd. Figure 7e is the most complete cooking pot recovered from the Honiavasa site, and illustrates a tendency towards very gentle vertical curvature of the neck which can make neck sheds from the site difficult to identify. Figure $7 \mathrm{f}$ from the Zangana site is a large and particularly thin sherd with a sharp, although slightly thickened inflection in the neck profile, and is broadly comparable to the dated Hoghoi sherd. Figure $7 \mathrm{~g}$ is a particularly thin-rimmed and thin-bodied sherd from the Miho site which differs from the dated Hoghoi sherd in having typical Miho-phase thickening of the neck interior in the profile, thus providing a poor match. Figure $7 \mathrm{~h}$, from Miho, is better, being a tall thin rim without thickening of the neck, but as is the case with many thin-profiled neck sherds, is broken at the neck and thus provides a poor basis for comparison. The same holds for Figure 7i, from Zangana. Figure 7j shows a sherd from Miho which is suitably thin and sharply inflected at the neck, emphasizing the links between Miho phase and the dated Hoghoi sherd. Figures 4k, 1, m and $\mathrm{n}$ are the sort of rims that potentially could be from the dated Hoghoi 


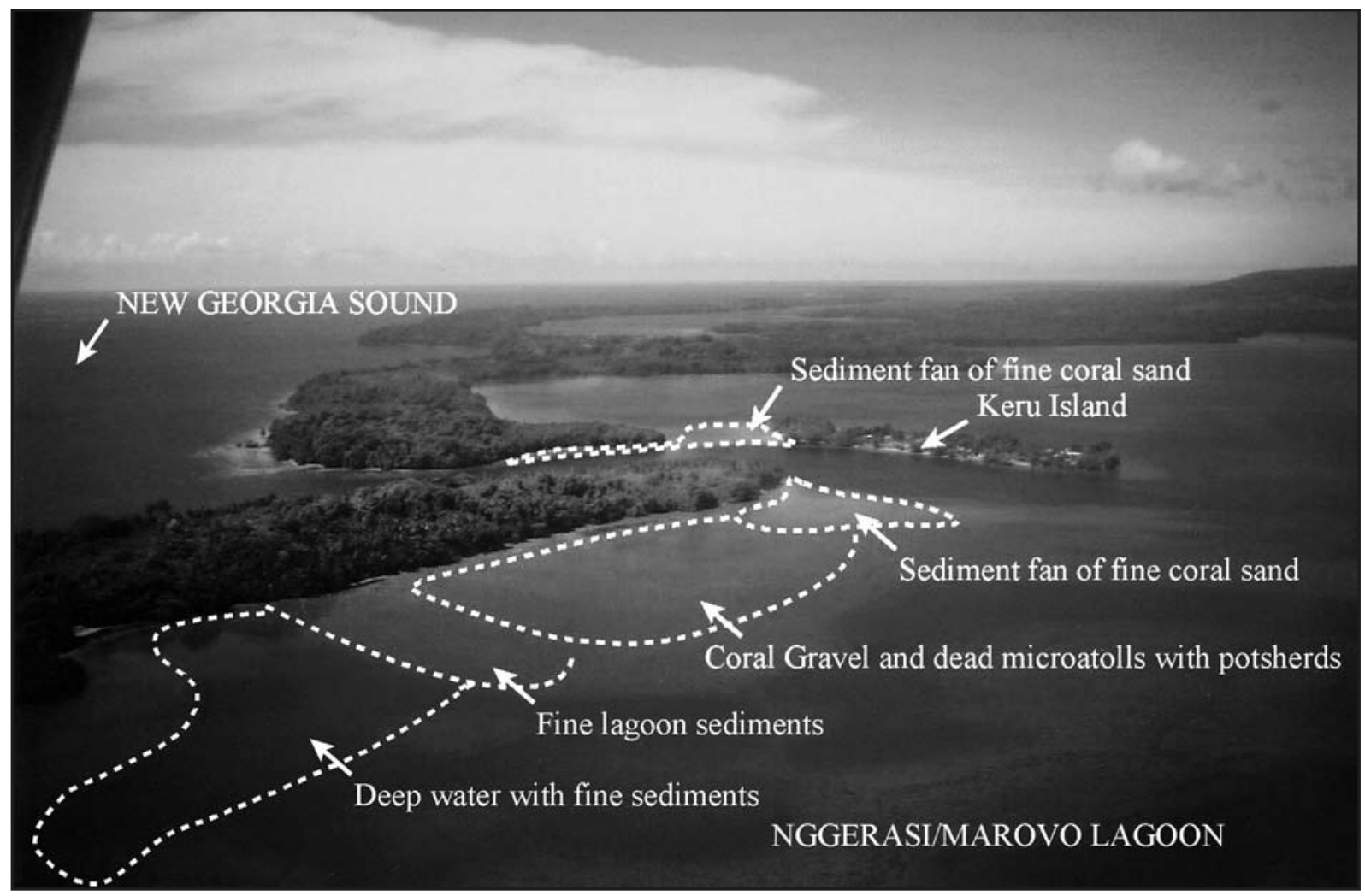

Figure 6. The Lolomo site, situated just to the north of the Keru passage into Ngerrasi Lagoon, showing sediment zonation.

sherd, being everted, thin and tall, but the necks are incomplete or missing, illustrating the difficulties of extrapolating from the Hoghoi radiocarbon date using ceramic style/form.

\section{New Data From Lolomo}

As part of a Wenner-Gren funded research project, underwater survey was conducted in the Nggerasi and Marovo lagoons (Figure 2). An underwater ceramic distribution measuring 250 metres by 70 metres was located at Lolomo (Figure 6). The Lolomo site was much more deeply immersed than other scatters on the mainland shore, and several weeks spent diving resulted in the recovery, recording and sampling of 413 sherds, many of them large and well-preserved, in one case being approximately one-third of a whole vessel. Collection zones of approximately 1-metre radius were marked by long stakes of a heavy wood that was not buoyant, and locations of these were surveyed by theodolite, along with shoreline profiles. These locations provide approximate spatial provenance for the sherds (the distribution of found sample locations is shown approximately in Figure 8). All sherds were desalinated in rainwater, dried, drawn and photographed. Temper samples were taken for analysis, and the sherds were returned to their found locations in the sea. A steel datum point for the theodolite survey was cemented into the coral beach and its location recorded by handheld GPS. This data has not yet been written up in detail for publication. Analysis of ceramic variability and spatial analysis is underway. The new data will only be briefly introduced here, insofar as it is relevant to Sheppard and Walter's interpretation of the Hoghoi radiocarbon date. 


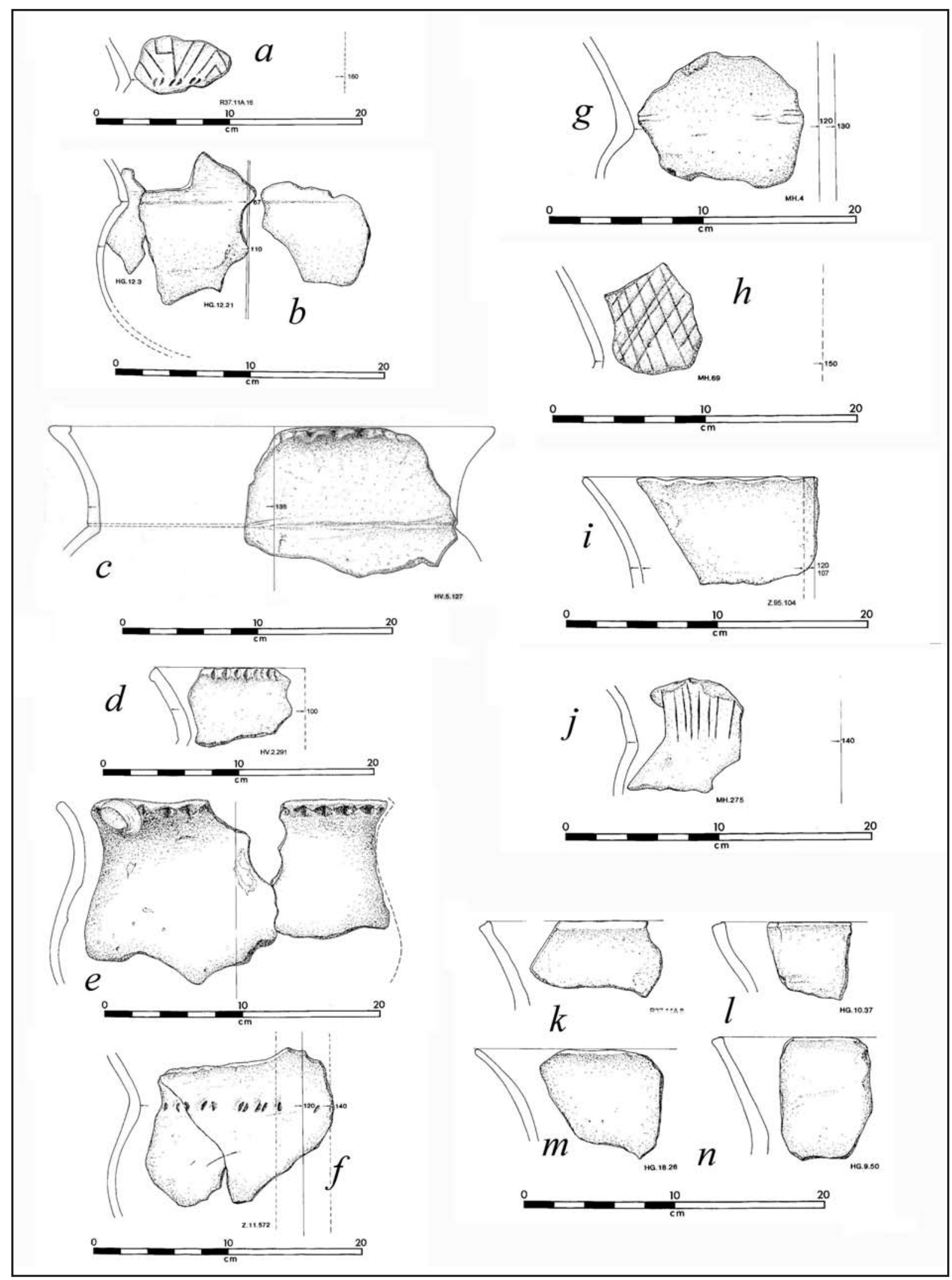

Figure 7. Significant sherds from the Roviana series in relation to the radiocarbon date from Hoghoi. 


\section{Lolomo Site Physiography}

The barrier islands of the New Georgia lagoon system are composed of Plio-Pleistocene reefs with a complex tectonic history, resulting in multiple reef formations approximately concentric with the New Georgia volcanic cones. These barrier islands have fringing reefs of Holocene age, uplifted to varying extents (Dunkley 1986; Mann et al. 1998). In general the Roviana lagoon barrier islands and mainland shore are notable for a shoreline flat covered in relatively fresh fragmented acropora corals, except where mainland rivers provide a sediment supply and create fine-sediment fans and swampy deltas, while the Nggerasi Lagoon barrier islands lack this evidence for very recent uplift, tending to have a shore platform covered in terra rossa weathered reefal soils. Data on this has not been collected, this is a very preliminary observation only, requiring more detailed examination. One characteristic common to all the barrier islands around New Georgia is a low sediment supply with consequent high archaeological visibility in the sea. There are no rivers on any of these islets, and sediment from mainland rivers is deposited as deltaic fans forming muddy shorelines, with consequent low archaeological visibility in their vicinity.

The Lolomo site is situated along the lagoon shore of the barrier island forming the northern shore of the Keru Reef Passage (Ramata Island), on which there is an airstrip (out of action at the time of fieldwork, due to a lawnmower breakdown, necessitating an $80 \mathrm{~km}$ canoe trip from Munda). Sediment zonation along the Ramata Island lagoon-side shoreline is shown in Figure 6. If a Lapita site was present and is preserved at the Keru Reef passage, it will be under the fine coral sands either side of the lagoon end of the reef passage. The sediment supply for these fans is most likely the abrasion of Plio-Pleistocene coral boulder shorelines along the reef passage, where wave exposure is considerable at times in some weathers. This is a major contrast to the inner end of the Honiavasa reef passage of Roviana Lagoon, where both the Honiavasa and Miho sites are located, which have very little build-up of sand.

\section{Significance of the Lolomo Ceramics}

In analysing sherds recovered from the sea at Roviana Lagoon, it was hypothesised that a tall, thin, weak rim form was likely to be characteristic of the Miho ceramic style, the latter thought to postdate Roviana Lapita ceramics from Honiavasa (Felgate 2003:385-386). The dated Hoghoi sherd had a neck form unlike the typical Miho thickened neck profile, however, but had a thin everted rim, too tall to fit comfortably into the Gharanga style of short, heavily-everted rim. The deeper water in which the Lolomo site is located has resulted in better preservation of fragile tall thin rim forms, of which there are numerous examples in the Lolomo sample.

Some of the tall thin rims recorded from Lolomo correspond to the hypothesised Miho-phase form, but differ from the dated Hoghoi sherd in having a thickened neck profile and gentle external vertical curvature at the neck restriction (these are characteristics of the Miho Phase, and some plain sherds of this general form were present in the Honiavasa site also). A sherd recovered from Lolomo illustrates this (see Figure 9c). Thinnecked everted-rim sherds consistent with the dated Hoghoi sherd were also found at Lolomo (Figures 9f, $6 \mathrm{~g}$ and $6 \mathrm{~h}$ ). The sherds lie in the dense deposit of ceramics at the north-western edge of the site Figure 8), in water of about $2.5 \mathrm{~m}$ depth at the time of collection and well buried in sand and gravels, hence the good state of preservation of these fragile neck forms.

While there is considerable form variability between these three vessels, they are all even thinner than the dated Hoghoi sherd but provide the closest match so far to the unusual Hoghoi neck, illustrating the biasing effect of differential preservation on our available information concerning vessel form.

It must be stressed that neither Hoghoi nor Lolomo are Lapita sites, although both are very clearly Lapita derived, permitting phyletic seriation. This is apparent for example, in the twinned vertical decorative elements used as design zone markers for Miho-phase ceramics, examples of which occur at Lolomo (Figure 9c). Where this differs from the Honiavasa carinated jars, in terms of the design system, is the absence of twinned horizontal decorative elements. This twinned or sometimes tripled horizontal design zone marker is very much a feature of most geometric Lapita design, and it looks to have partially broken down in the Lolomo 


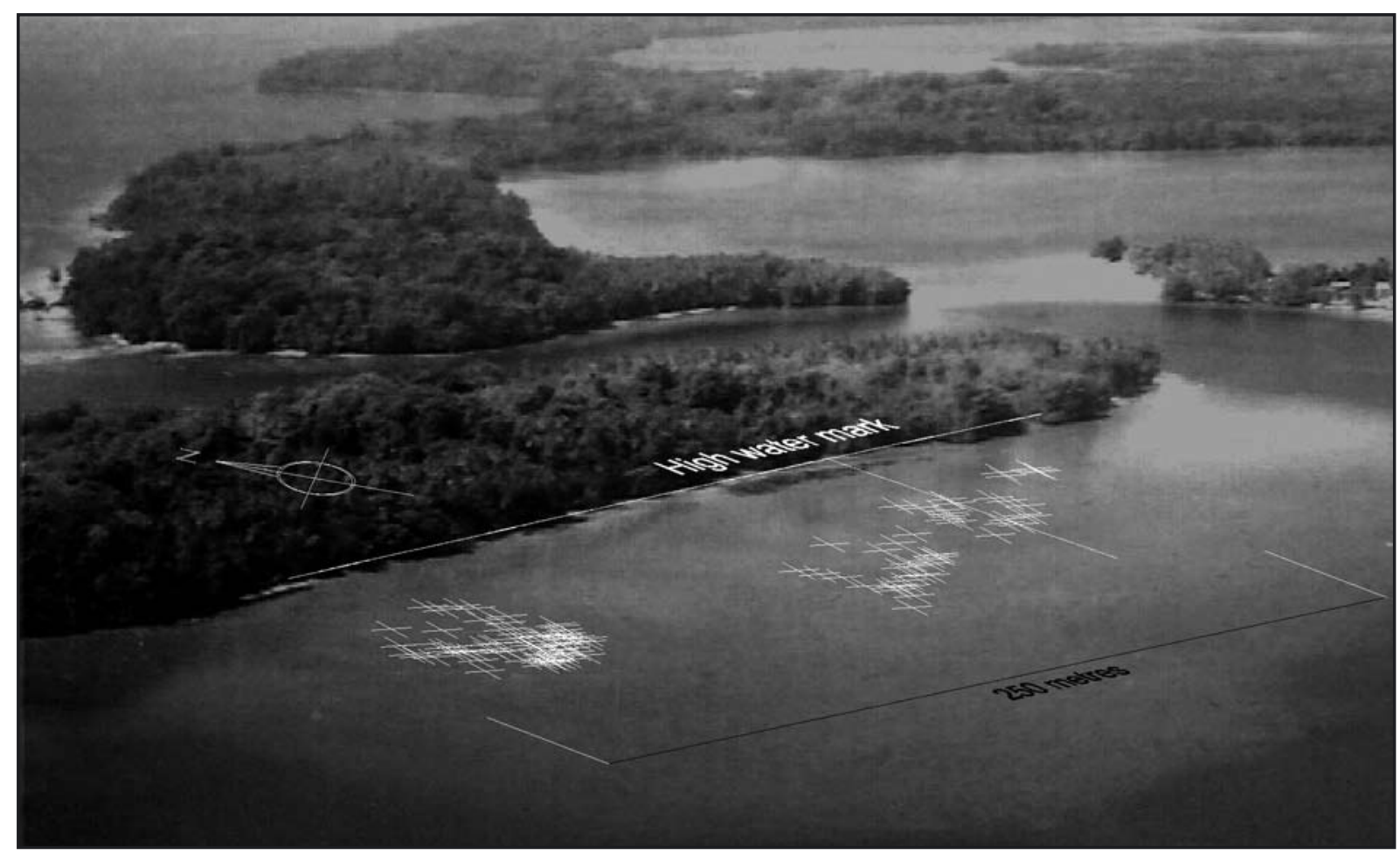

Figure 8. An approximate overlay of survey data from Lolomo on an oblique aerial photograph. The white crosses are surveyed stakes marking underwater collection provenance zones from which pottery was recorded.

decoration, which tends more towards the Miho-style unbounded designs (there are examples of Gharanga and Kopo style decoration and corresponding forms also at Lolomo).

There are no examples of the strongly-carinated Honiavasa slab-built Lapita jars at Lolomo. These are clearly a feature of Lapita almost everywhere, all the way to Tonga, including Honiavasa and Poitete, and other occasional find spots at Roviana lagoon. A jar of this sort recently recovered from Honiavasa during a second collection of the site is illustrated in Figure 9e, providing a good decorative match to a Poitete vessel illustrated by Summerhayes and Scales (Summerhayes and Scales 2005:Figure 3e).

At Lolomo there are none of the compound rims characteristic of the Honiavasa Lapita site, and characteristic of Lapita at Buka, especially at DJQ DES and on the outer reef edge at DAF (Wickler 2001:7981 and see Wickler's Figure 4.2) and also found as far east as Tonga (Poulsen 1987). A second collection at Honiavasa recovered three more of these (one is illustrated in Figure 9j).

The absence of characteristic Lapita forms from both Lolomo and Hoghoi, and the presence of the fragile neck form in both sites provides additional support for assignment of the Hoghoi date to the MihoGharanga phase of the series. A number of Gharanga-style rims are present in the Lolomo site (not illustrated), which supports this conclusion. There was one sherd with a single line of dentate stamping at Lolomo (Figure 9a), as well as two open bowls with slight carination/ restriction (Figure 9b and 6d) as well as one incised (?Lapita) small everted excurvate form that is unlike anything found in the Western Solomons so far (Figure 9i).

The dated Hoghoi sherd seems to me to be intermediate in form between Miho-phase and Gharanga phase, and, to make a just-so-story out of it, made at a time when pottery is becoming so thin and finely made that the tall Miho-Style rim form with thickened neck is gradually giving way to the Gharanga style of short, heavily-everted rim, as a way of retaining the strength of the vessel neck. Reduction in thickness (and concurrent reduction in thickness variability) would confer better thermal properties for cooking, and possibly better firing survival rates and shorter drying times prior to firing, as well as less thermal stress during firing and use. 


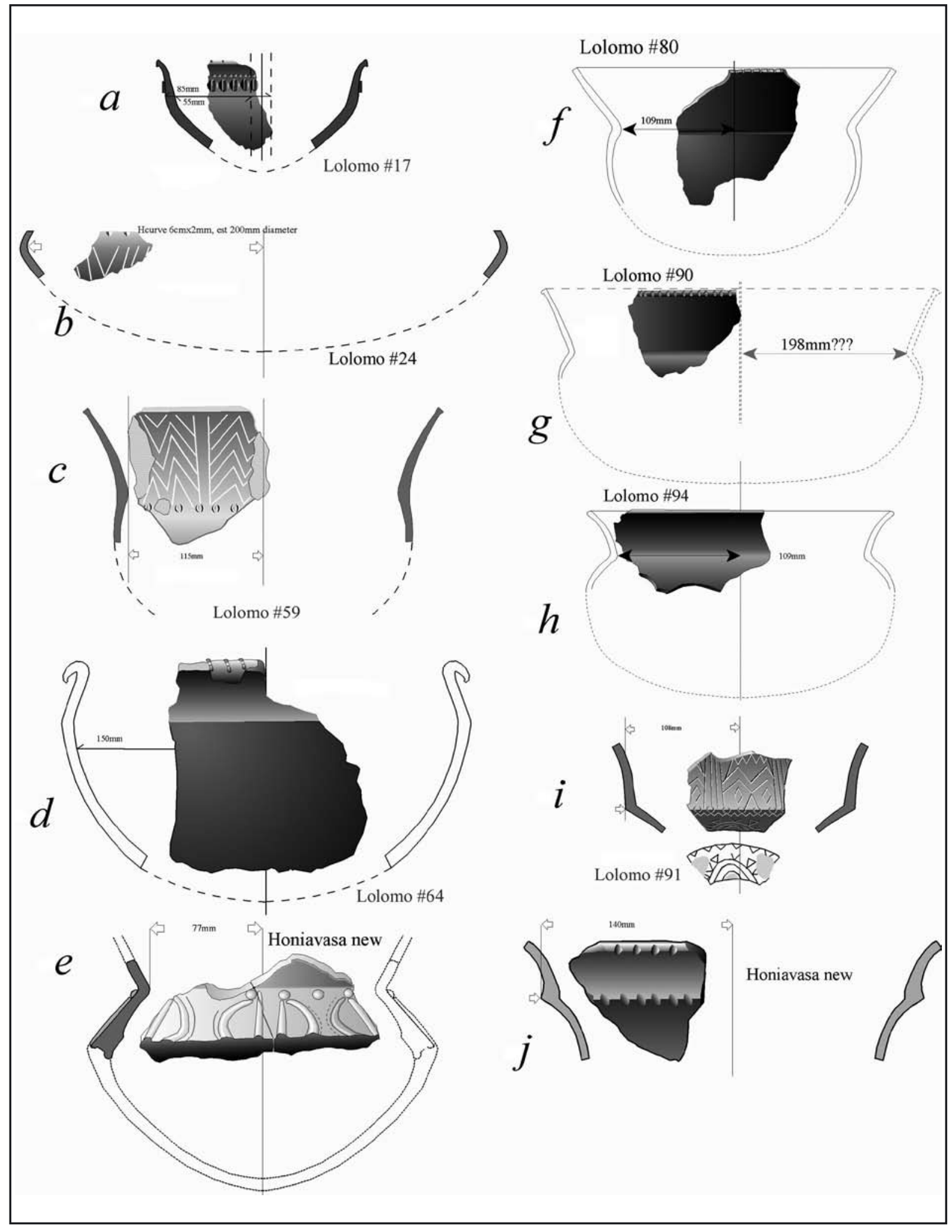

Figure 9. A selection of pottery finds from Lolomo and Honiavasa. 


\section{New Pottery finds from Honiavasa: Strengthening the link to Poitete}

Honiavasa, at Roviana Lagoon (Figure 2) was revisited in the course of the North New Georgia Lapita Pottery Project, during the season of daytime low tides (initial collection had been in midsummer in difficult roughweather rising-tide conditions) and an additional deeper part of the site was discovered adjacent to the main Honiavasa reef passage. New pottery finds from Honiavasa strengthen the link between the small Poitete sample and Honiavasa (compare Figure 3e of Summerhayes and Scales (2005) with Figures 6e in this paper). The greater incidence of dentate decoration in the Poitete sample than at Honiavasa provides an even clearer link to the Buka reef sites than that noted after the initial collection from Honiavasa, although overlapping rather than identical occupation spans may be a factor in the differences between the Poitete sample and that from Honiavasa.

\section{Conclusion: the age of the Honiavasa site}

I sestimate the age of the Honiavasa carinated jars with horizontally bounded decoration to be somewhere in the period 3000 to 2800 BP. I personally don't see sufficient difference between the Reef/Santa Cruz assemblages from RF2, early New Caledonian and Vanuatu Lapita pottery, the Poitete pottery, and Wickler's Buka reef pottery to conclude that the people responsible for the RF-2 pots were anything but closely related in terms of cultural phylogeny to those at Honiavasa. The similarities are more marked in terms of vessel form than in terms of decorative technique in the case of Honiavasa (but decorative structure is another thing- we should avoid dentate-centrism). The principal difference in terms of form is the absence of RF-2 broad everted-rim serving-dish forms, with stands, (although one possible stand was recovered from the Zangana site in Roviana Lagoon). These differences could easily be taphonomic, as the sherds recovered from the Honiavasa site were mostly robust and well-fired, being either heavily carinated slab-built vessels (interpreted as fluid transport forms- most probably water-carrying jars with a high use and breakage rate) or globular cooking pots, similarly with a high breakage rate according to ethnoarchaeological theory.

\section{Interpreting the Evidence: Lapita Limping rather than Leapfrogging}

Sheppard and Walter review the pollen-core evidence from the Solomons, in support of late-Lapita influx rather than early. They note that Haberle's Laukutu swamp core (Haberle 1996) shows fluctuation in the level of charcoal after 3200BP, but that a dramatic rise occurs later in that core, and that similar dramatic and sustained rises are happening about $2600 \mathrm{BP}$ in the Roviana cores under analysis by Grimes (unpublished). They note the correlation of this rise with the date from the Hoghoi sherd from Roviana lagoon, although it is worth pointing out that the Hoghoi sherd could date as early as 2900 BP at 95\% confidence limits.

Early Lapita colonists must have trod lightly in the Near-Oceanic Solomons. If the Hoghoi sherd substantially postdates the Lapita sites of Poitete and Honiavasa (which is supported by both ceramic seriation and thermoluminescence relative chronology), more thought needs to be given to the possibility that the early fluctuations in charcoal influx are consistent with the presence of a low-density Lapita settlement pattern of intertidal sites in the Western Solomons beginning somewhere around 3200 BP. I cannot see that there are four to five centuries between the early well-dated Reef/Santa Cruz Lapita sites and the Buka/ West Solomons reef Lapita sites, but certainly could accept this for the later Buka/West Solomons reef sites, where characteristic Lapita vessel forms and design structure have been largely lost, and unbounded decoration is the norm. The dramatic and sustained rise in charcoal influx about 2600 BP (Sheppard and Walter 2006) under this scenario 
correlates with the dramatic infill of the intertidal/subtidal ceramic distribution, in the form of the many sites with Miho and Gharanga/Kopo styles at Roviana, North New Georgia, Marovo, Gizo and Tanahuka on Kolombangara.

\section{Taphonomy}

The Roviana pottery from the sea has had a hammering, and only a tiny proportion of the discarded sherdage remains to be found as a general rule, and this in localities extraordinarily well sheltered from the effects of cyclone and tsunami (Felgate 2003:247-286). This means that taphonomic biases are highly likely - sherds need to have been strong and lucky to have survived millennia of relatively sheltered water processes. This has implications for ceramic seriation in the Near-Oceanic Solomon Islands, and comparison of like-with-like, in a taphonomic sense, is important in such circumstances (Felgate and Bickler n.d). This means that at present the principal sites with which to compare the recent finds of Lapita and post-Lapita in the Western Solomons are the Buka reef sites (Wickler 1995, 2001) and the Poitete material from Kolombangara. Wickler collected 60 000 sherds from Buka, the Roviana sample was around 3,000 (initial sherd count at Honiavasa was 442, while a second collection in the course of the North New Georgia Lapita Pottery Project yielded an additional 93 Honiavasa sherds, generally fairly large). There were 28 sherds collected from Poitete, 15 of them decorated.

\section{Long distance exchange}

Sheppard and Walter are thus far correct in characterising Reef/Santa Cruz long-distance exchange as unique in terms of the evidence for long-distance large-scale sourcing of Talasea obsidian from New Britain (but see Galipaud and Swete-Kelly this volume for new data from northern Vanuatu). There are tantalising hints that very-long-distance links were maintained by Lapita people at Honiavasa too, and into the post-Lapita period also at nearby sites. While none of the lithic materials have yet been unequivocally sourced, these sites do contain a great diversity of imported lithic resources, including stone tools and abraders, and of course the anomalous granitic-hybrid pottery temper, thought to be indicative of tropical continental margin geological origin (Felgate and Dickinson 2001). Expert opinion has shifted slightly recently to the granite islands of the Queensland coast as the most attractive source for this sand on geoarchaeological grounds (Dickinson 2006:115). It should also be noted that one sherd matching the Roviana volcanic placer temper was recovered from Bellona in Remote Oceania (Dickinson 2006:115). A conclusion that the Reef /Santa-Cruz obsidian shows that Reef/ Santa Cruz Lapita people were the only Lapita settlements to maintain such long-distance contacts, and that they were not receiving obsidian from intermediate early-Lapita settlements elsewhere in the Solomons (as yet undiscovered) may turn out to be premature.

The possibility of some sort of down-the-line exchange should not be ruled out until we have satisfactorily excluded the possibility of undiscovered (submerged ?) early Lapita sites around Malaita, for example (preferably supported by detailed sea-level studies). The absence of obsidian in inland sites such as Vatuluma Posovi on Guadalcanal doesn't demonstrate a lack of down-the-line exchange until the absence of coastal Lapita sites with Talasea obsidian is demonstrated. Avoidance theorists cannot have their cake and eat it too: if people are avoiding the main Solomons to some extent because of hostile NAN prior inhabitants, they would hardly be fraternising with NAN speakers in Vatuluma Posovi cave on Guadalcanal over a good chunk of obsidian, which would explain the absence of Talasea obsidian in Lapita-age deposit from that excavation, but certainly might have done so with hitherto-undiscovered Lapita coastal colonists in the general area. Cherts were moving out from the Solomons (Sheppard 1993), so it is not as though the Reefs/Santa Cruz were not 
in contact with anyone but Talasea. There is recent evidence for links to central north Vanuatu also (Bedford pers. comm.). It does seem clear that Reef/Santa Cruz Lapita people were highly desirous of Talasea obsidian, to have acquired it in such quantity, suggesting a strong cultural link to Talasea.

\section{Survey methods and evidence of absence}

Sheppard and Walter open a review of Lapita in the Solomons with the question "Are there any Lapita sites in the Solomons?" The central thesis emerging from my eight-year study of Lapita and its derivatives in the Western Solomons (Felgate 2003) is that we cannot read the Lapita archaeological record in that region without concerted programs of littoral geo-archaeology, including sea-level studies. My conclusion on examining existing evidence in 2003 was that the Lapita gap, if it hadn't already been filled, would completely disappear if appropriate surveys were targeted at places where Lapita stilt-settlements were: a) likely to have been located; b) likely to have been preserved; and c) are reasonably accessible to the archaeologist (which might involve underwater archaeology gear). Sheppard and Walter concede that the absence of evidence for stilt house villages from the Central Solomons cannot be said to be a change in settlement pattern without "some targeted surveys of intertidal sheltered areas in Remote Oceania". Some targeted surveys in Near Oceania may be more appropriate, as clearly there is a voluminous terrestrial Lapita record in Remote Oceania, suggesting either a founder effect or environmental factor that made terrestrial settlement more feasible. Regarding the latter possibility, it should be remembered that the Near/Remote Oceanic boundary is a biogeographic one, involving some dangerous and discomfiting fauna that might encourage living off the ground, and over water, in Near-Oceania.

Sheppard and Walter argue for absence of Lapita in the New Georgia group. They consider that, for the sites with dentate-stamp pottery currently known, that

"...the remainder of the decorated assemblage is composed of ceramics that seem identical in all respects to the incised and applied relief tradition of the Bismarck Archipelago" (Sheppard and Walter 2006).

I have argued in detail elsewhere that the temporal conflation of various admixtures of various periods is a major problem in the archaeology of Lapita and its derivatives throughout Near Oceania, and see the definition of Post-Lapita sequences as a subject still in its infancy.

\section{Lapita Limping}

The leap-froggers may be partly right in that Lapita is far less common in the intertidal/subtidal record from the Western Solomons than later derivatives. I concluded in my thesis that we have every reason from the data at hand to consider our Lapita sample from the Near-Oceanic Solomons to be "unsaturated" in Kintigh's sense (Kintigh 1984). I believe this to be true even of the ubiquitous Post-Lapita pottery from the sea, which is much more easily found. The Lolomo post-Lapita pottery under analysis provides ample new information, as will each new site in the foreseeable future.

The current data indicate very clearly that Lapita is far less common and more difficult to find in New Georgia than Post- Lapita pottery. By extension, our Lapita sample from New Georgia is less saturated than our post-Lapita sample. This goes beyond differential preservation, as the robust Honiavasa and Poitete jars are clearly able to withstand the rigours of deposition in the sea in some cases. This suggests that Lapita demographic increase in this region was slow rather than explosive, unlike Remote Oceania, where the early Lapita signal is far stronger. It should be borne in mind also that the overall quantities of Lapita tend to be large in Remote Oceania and the Bismarcks due to vastly greater sediment supply in the form of tephras, 
hence good preservation, in combination in the case of Remote Oceania with numerous examples of terrestrial primary deposition.

Groube (ironically in the course of noting the contradiction of the lack of a community of culture between Australia and Island Melanesia) suggested that the "predators within" profoundly affected patterns of prehistoric social development (Groube 1993). Malaria or complications arising from malarial illness are the biggest killers of children today in Near Oceania, and otherwise healthy adults are ravaged by the disease and its complications such as pneumonia and brain damage.

The predators without may have been a factor also in Lapita limping in the Solomons and elsewhere where it should be but has not been found. Present in Near-Oceania were pre-Lapita populations who may also have taken their toll initially on small-scale intrusions of culturally distinct people 3000 years ago (the same holds for any putative Lapita colonists of Australia). In addition, predation by crocodiles would have been a far more significant factor in Near Oceania 3000 years ago than we see today. Crocodile populations are relatively young today in Near/Oceanic Island Melanesia due to heavy hunting until about thirty years ago, and are only becoming more obstreperous towards humans in recent years.

Compounding the complications posed by deposition in the sea, we should expect therefore that early Lapita settlement would limp demographically in Near Oceania in comparison to Remote Oceania. And this is consistent with the record from the Solomons. Moore's (2001:396, 406) "string of pearls" model cited by Green (2003:113) in relation to Lapita migration can be expected to have been more thinly strung in Near Oceania, and be a more discreet adornment beyond its successful start in the Bismarck Archipelago. Perhaps limping might be a better characterisation than leapfrogging.

As I write it is getting late, and I must wake in the small hours to catch an aeroplane in which to pursue sand samples pointing to Lapita colonists in North Queensland. The deadline for this paper has expired. I present it in unfinished form.

\section{Postscript}

This paper was revised on return from Queensland, but I like the ending, and leave it in its abrupt form, as it expresses both the constraints of being an unpaid researcher who must fit academic publication in between the business of attempting to make a living by other means, and also expresses the confident anticipation that one's theory is on track and is successfully predicting the physical evidence, which I suspect is the satisfaction that drives many of us to spend our lives doing this.

\section{Acknowledgements}

The research at Lolomo was made possible by a postdoctoral fieldwork grant from the Wenner-Gren Foundation. I gratefully acknowledge a grant from the Green Foundation. Without such support and recognition this paper would have been so much more difficult to write. The research at Lolomo was carried out with institutional support from the University of Auckland Anthropology Department, especially Peter Sheppard. I wish to acknowledge the research permission granted by the Solomon Islands Ministry of Education, and locally by the Christian Fellowship Church. Support from Lawrence Foanaota, Kenneth Roga, Solomon Roni, James Agolo and the Reverend Opportunity Kuku is gratefully acknowledged in that regard. Fieldwork was carried out by a team of four divers from Roviana and Keru, and the hospitality of the Pule family is remembered with gratitude. Stuart Bedford read the first draft and improved the paper as did Matthew Spriggs with a later version. 


\section{References}

Allen, J., C. Gosden and J.P. White 1989. Human Pleistocene Adaptations in the Tropical Island Pacific: Recent Evidence from New Ireland, a Greater Australian Outlier. Antiquity 63: 548-561.

Bronk Ramsey, C., 2005. OxCal version 3.10 Radiocarbon Calibration software. < http:/ / c14.arch.ox.ac.uk/embed. php?File=oxcal.html >

Dickinson, W. R. 2006. Temper Sands in Prehistoric Oceanian Pottery: Geotectonics, Sedimentology, Petrography, Provenance. The Geological Society of America Special Paper 406.

Doran, E., 1973. Nao, Junk and Vaka: Boats and Culture History. Texas A\&M University: University Lecture Series.

Dunkley, P. N. 1986. The Geology of the New Georgia Group, Western Solomon Islands. British Technical Cooperation Report, Western Solomon Islands Geological Mapping Project.

Felgate, M. W. 2001. A Roviana Ceramic Sequence and the Prehistory of Near Oceania: Work in Progress. In G. R. Clark, A. J. Anderson and T. Vunidilo (eds), The Archaeology of the Lapita Dispersal in Oceania, pp.39-60. Canberra: Pandanus Press, Terra Australis 17.

Felgate, M.W. 2003. Reading Lapita in Near-Oceania: Intertidal and Shallow-Water Pottery Scatters, Roviana Lagoon, New Georgia, Solomon Islands. PhD thesis, University of Auckland.

Felgate, M. W. and S. H. Bickler n.d. Pots as Species: Estimating a Parent Population of Vessels from a Sherd Sample. Unpublished manuscript in the possession of the authors.

Felgate, M. W. and W. R. Dickinson 2001. Late-Lapita and Post-Lapita Pottery Transfers: Evidence from IntertidalZone Sites of Roviana Lagoon, Western Province, Solomon Islands. In M. Jones and P. J. Sheppard (eds), Proceedings of the 2001 Australasian Archaeometry Conference, pp.105-122. Auckland: Research Papers in Anthropology and Linguistics, Number 5.

Gorecki, P. 1992. A Lapita Smoke Screen ? In J-C. Galipaud (ed.), Poterie Lapita et Peuplement, pp.27-47. Nouméa: ORSTOM.

Green, R. C. 1978. New Sites with Lapita Pottery and Their Implications for an Understanding of the Settlement of the Western Pacific. Auckland: University of Auckland, Working Papers in Anthropology, Archaeology, Linguistics and Maori Studies 51.

Green, R.C. 1991a. The Lapita Cultural Complex: Current Evidence and Proposed Models. Bulletin of the Indo-Pacific Prehistory Association 11: 295-305.

Green, R.C. 1991b. Near and Remote Oceania: Disestablishing “Melanesia” in Culture History. In A. Pawley (ed.) Man and a Half: Essays in Pacific Anthropology and Ethnobiology in Honour of Ralph Bulmer, pp.491-502. Auckland: The Polynesian Society.

Green, R.C. 2003. The Lapita horizon and traditions - Signature for one set of oceanic migrations. In C. Sand (ed.), Pacific Archaeology: assessments and prospects Proceedings of the Conference for the 50th anniversary of the first Lapita excavation. Kone-Noumea 2002, pp. 95-120. Noumea: Les Cahiers de l'archeologie en Nouvelle-Calédonie 15.

Groube, L. 1993. Contradictions and Malaria in Melanesian and Australian Prehistory. In M. Spriggs, D. Yen, W. Ambrose, R. Jones, A. Thorne and A. Andrews (eds), A Community of Culture: The People and Prehistory of the Pacific, pp.164-186. Canberra: Department of Prehistory, Australian National University. Occasional papers in Prehistory 21.

Haberle, S. G., 1996. Explanations for Paleoecological Changes on the Northern Plains of Guadalcanal, Solomon Islands: The Last 3200 Years. The Holocene 6: 333-338.

Haddon, A. C. and J. Hornell 1937. Canoes of Oceania Volume II: The Canoes of Melanesia, Queensland and New Guinea. Honolulu: Bishop Museum Press, BP Bishop Museum Special Publication 28.

Hornell, J. 1936. Boat Construction in Scandinavia and Oceania: Another Parallel in Botel Tobago. MAN XXXVI:200-232.

Kintigh, K. W. 1984. Measuring Archaeological Diversity by Comparison with Simulated Assemblages. American Antiquity 49 (1):44-54. 
Kirch, P. V. 1997. The Lapita Peoples: Ancestors of the Oceanic World. Oxford: Blackwell.

Kirch, P. V. and T.L. Hunt 1988. The Spatial and Temporal Boundaries of Lapita. In P. V. Kirch and T. L. Hunt (eds), Archaeology of the Lapita Cultural Complex: A Critical Review, pp.9-31. Seattle: Thomas Burke Memorial Washington State Museum Research Report No. 5.

Mann, P., F.W. Taylor, M.B. Lagoe, A. Quarles and G. Burr 1998. Accelerating Late Quaternary Uplift of the New Georgia Island Group (Solomon Island Arc) in Response to Subduction of the Recently Active Woodlark Spreading Centre and Coleman Seamount. Tectonophysics 295: 259-306.

Moore, J.H. 2001. Evaluating five models of human colonization. American Anthropologist 103:395-408.

Poulsen, J. 1987. Early Tongan Prehistory. Canberra: Department of Prehistory, Australian National University, Terra Australis 12.

Reeve, R. 1989. Recent Work on the Prehistory of the Western Solomons, Melanesia. Bulletin of the Indo-Pacific Prehistory Association 9: 44-67.

Roe, D. 1992. Investigations into the Prehistory of the Central Solomons: Some Old and Some New Data from Northwest Guadalcanal. In J-C. Galipaud (ed), Poterie Lapita et Peuplement, pp.91-101. Nouméa: ORSTOM.

Roe, D. 1993. Prehistory without Pots: Prehistoric Settlement and Economy of Northwest Guadalcanal, Solomon Islands. PhD thesis, Australian National University.

Ross, M. 1988. Proto-Oceanic and the Austronesian Languages of Western Melanesia. Canberra: Department of Linguistics, Australian National University. Pacific Linguistics, Series C - No. 98.

Sergeantson, S. W. and X. Gao 1995. Homo Sapiens Is an Evolving Species: Origins of the Austronesians. In P. Bellwood, J. J. Fox and D. Tryon (eds), The Austronesians: Historical and Comparative Perspectives, pp.165180. Canberra: Australian National University.

Sheppard, P. J. 1993. Lapita Lithics: Trade/Exchange and Technology. A View from the Reefs/Santa Cruz. Archaeology in Oceania 28:121-137.

Sheppard, P. J., M.W. Felgate, K. Roga, J. Keopo and R. Walter 1999. A Ceramic Sequence from Roviana Lagoon (New Georgia, Solomon Islands). In J-C. Galipaud and I. Lilley (eds), The Pacific from 5000 to 2000 BP: Colonization and Transformations, pp.313-322. Paris: Editions de IRD.

Sheppard, P. and R. Walter 2006. A Revised Model of Solomon Islands Culture History. Journal of the Polynesian Society 115 (1): 47-76.

Spriggs, M., 1997. The Island Melanesians. Oxford: Blackwell.

Stuiver, M., P.J. Reimer, E. Bard, J.W. Beck, G.S. Burr, K.A. Hughen, B. Kromer, G. McCormac, J. van der Plicht and M. Spurk 1998. INTCAL98 radiocarbon age calibration: 24000-0 BP. Radiocarbon 40:1041-1083.

Summerhayes, G. and I. Scales 2005. New Lapita Pottery Finds from Kolombangara, Western Solomon Islands. Archaeology in Oceania 40:14-20.

Terrell, J. E. 1976. Perspectives on the Prehistory of Bougainville Island, Papua New Guinea: A Study in the Human Biogeography of the Southwestern Pacific. PhD thesis, Harvard University.

Tryon, D. T. and B.D. Hackman 1983. Solomons Islands Languages: An Internal Classification. Canberra: Department of Linguistics, RSPacS, Australian National University, Pacific Linguistics Series C. 72

Waterhouse, J. H. L. 1949. A Roviana and English Dictionary: With English-Roviana Index, List of Natural History Objects and Appendix of Old Customs. Sydney: Epworth Publishing and Printing House.

Wickler, S. 1995. Twenty-Nine Thousand Years on Buka: Long-Term Cultural Change in the Northern Solomon Islands. PhD thesis, University of Hawaii.

Wickler, S. 2001. The Prehistory of Buka: A Stepping Stone Island in the North Solomons. Canberra: Department of Archaeology and Natural History and Centre for Archaeological Research, Australian National University, Terra Australis 16.

Wickler, S. and M. Spriggs 1988. Pleistocene Human Occupation of the Solomon Islands, Melanesia. Antiquity 62: 703-706. 